\title{
Study of the cell biology and biochemistry of cherubism
}

\author{
John Southgate, Usha Sarma, John V Townend, Jeffrey Barron, Adrienne M Flanagan
}

\begin{abstract}
Aims-To establish whether the multinucleate cells in lesions of patients with cherubism are also osteoclasts and if this is the case whether they were responsive to calcitonin; to carry out cytogenetic studies on two members of the same family affected by cherubism in an attempt to identify any major chromosomal defects; and to perform an in-depth modern biochemical study of four children in the same family.

Subjects and methods-Four related children with cherubism were studied. Tissue taken from one of the children at elective decompression of an optic nerve was submitted to in vitro bone resorption studies. Cytogenetic studies were done on two of the children and biochemical studies on all four.
\end{abstract}

Results-The multinucleate cells in the cherubic lesions were shown to be osteoclasts since they synthesised tartrate resistant acid phosphatase, expressed the vitronectin receptor, and resorbed bone. Bone resorption by the cultured multinucleate cells was significantly inhibited by calcitonin. High resolution cytogenetic studies failed to detect any chromosomal abnormalities in two children with cherubism. The biochemistry profile of all four children with cherubism showed that serum calcium, parathyroid hormone, parathyroid related hormone, calcitonin, and alkaline phosphatase were within normal levels. Urine analysis of pyridinium and deoxypyridinium cross links, hydroxyproline, and calcium in relation to urine creatinine were measured to assess bone resorption in these children, and the values were at the upper end of the normal range in all four.

Conclusions-Further studies are required to determine whether calcitonin treatment will control this grossly deforming disease until the time when the physiological changes that occur at puberty rectify the pathology. It is not recommended that biochemical markers of bone resorption are used in isolation to monitor the activity of cherubism in individuals because the results are based on a small number of children and because of reports of marked interindividual variation in the levels of these markers, particularly in children. (f Clin Pathol 1998;51:831-837)

Keywords: cherubism; osteoclast; calcitonin; bone resorption; parathyroid hormone
Cherubism is a grossly deforming disease of the jaw and is generally inherited as an autosomal dominant trait, ${ }^{12}$ with incomplete penetrance and variable expressivity. ${ }^{1}$ Sporadic cases have also been reported. ${ }^{3-5}$ At birth, the jaw of the affected individuals is apparently normal and the disease usually presents between two and five years of age, although there is a report of the diagnosis being made as early as 18 months. ${ }^{6}$ The disease progresses until puberty, at which time it stabilises and regresses so that by the time the individuals are in their mid-twenties, their facial features are generally not recognised as having been affected by the disease. However, residual deformity of the jaws has been reported. ${ }^{67}$

In a typical case, painless symmetric, multilocular, radiolucent, expansile lesions develop at the angle and vertical ramus of the lower jaw. In more severely affected cases, the lesions ramify through both the upper and lower jaws, with extensive bone loss. This is associated with interference with tooth development, and premature tooth exfoliation may occur. Nonfacial bones are generally not affected, although bifid ribs have been reported. A further unexplained feature of the condition is marked cervical lymphadenopathy. ${ }^{68}$

The histology of this lesion is well described..$^{10}$ It comprises a mononuclear fibroblastic stroma in which large numbers of multinucleate cells are present and there may be cyst formation. Newly formed osteoid or bone is often seen at the periphery of lesional tissue. The histology is virtually identical to that seen in peripheral and central giant cell granulomata of jaw. ${ }^{11}$ Giant cell granuloma of the jaw and osteoclastoma are also histologically similar but the former is usually unilateral, whereas cherubism is a symmetric lesion, involving both sides of the jaw. Osteoclastoma rarely occurs at this site. The differential diagnosis of cherubism includes fibrous dysplasia and hyperparathyroidism, as these lesions also contain large numbers of osteoclasts. However, the histological features of fibrous dysplasia differ from those in cherubism in that, in the classical form, Chinese-figure-like trabeculae of immature bone, which are not rimmed by osteoblasts, are present within the proliferating stroma. Furthermore, polyostotic fibrous dysplasia first presents in the second or third decade (for a review, see Riefkohl et $a l^{12}$ ). Hyperparathyroidism, as opposed to cherubism, rarely affects the jaw in an isolated manner. The histology also differs from cherubism in that it does not contain the mononuclear stromal cell population which is characteristic of cherubism. Finally, peritrabecular fibrosis is 
Antecedents unknown

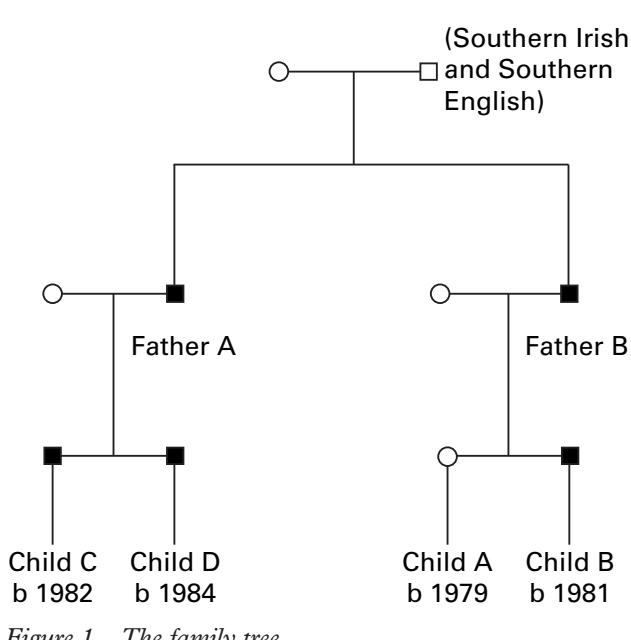

Figure 1 The family tree.

also a feature of hyperparathyroidism, but not of cherubism. Serum concentrations of parathyroid hormone and calcium also help to distinguish these lesions.

It has been shown previously that the multinucleate giant cells in osteoclastomas and giant cell granulomas of the jaw are osteoclasts, on the basis that these cells are able to resorb bone in vitro. ${ }^{13} 14$ Therefore one of the aims of this study was to establish whether the multinucleate cells in cherubic lesions are also osteoclasts and if this is the case whether they were responsive to calcitonin. Harris has previously reported the successful treatment of giant cell granulomata of the jaw with calcitonin, ${ }^{15}$ and this report prompted us to consider whether it might also be possible to treat cherubism with calcitonin. Such treatment may reduce the need for surgery and may result in early regression of the disease.

We also took the opportunity to carry out cytogenetic studies on two members of the same family affected by cherubism in an attempt to identify any major chromosomal defects. Finally we performed an in depth modern biochemical study of four children in the same family, as such a study does not at present exist.

\section{Case history}

The four children (A-D) shown in the simplified family tree (fig 1) inherited the disease known as cherubism through their affected fathers, who were brothers. The antecedents, many siblings, and descendants of the parents of the index cases (not shown) are notable for the absence of further cases. It is possible, therefore, that the disease arose as a recent mutation and only first presented clinically in the fathers of the children, though clearly the gene must have been present in one of the grandparents of the four children, as the affected fathers were not twins. The fathers remember having the disease in a mild form and we have confirmed this on being shown a photograph of them taken when they were about 10 years of age (not shown). In photographs of the fathers taken at the age of
18 , they no longer had recognisable features of the disease, which is consistent with its normal course.

Child A was first recognised as having cherubism at four years of age. The diagnosis was made on the basis of premature exfoliation of a deciduous lower incisor, marked bilateral cervical lymphadenopathy, and the discovery of the characteristic radiolucencies in both jaws. Since then the disease has progressed (fig 2 ), and has become more severe than it was in fathers A and B. Subsequent radiological examination of her cousins (child $\mathrm{C}$ at 20 months, and child $\mathrm{D}$ at two years) showed that they had similar disease. Child B is minimally affected, with radiolucencies only in both vertical rami of the lower jaw and possibly in both maxillary tuberosities. The condition has progressed steadily in children A, C, and D, and all three show marked facial deformities and displacement or loss of teeth (fig 3). Child A has been treated surgically for severe proptosis of her right eye and child $\mathrm{B}$ has had jaw surgery. Children A, C, and D are currently undergoing medical treatment for cherubism.

\section{Methods}

IN VITRO BONE RESORPTION STUDIES

Elective decompression of the right optic nerve was undertaken on the eldest of the four children (child A). Tissue was taken at the time of surgery and fixed in formalin for histological examination, "dabbed" onto glass slides for immunohistochemistry, and a small amount of fresh tissue placed in phosphate buffered saline (PBS) for tissue culture studies. The latter was transported to the laboratory on ice, where it was minced into tiny explants and sedimented onto wafers of devitalised bovine bone $(3 \times 3 \times$ $0.1 \mathrm{~mm}$ ), as described previously, ${ }^{16}$ in a 24 well plate (Sterilin) containing Medium 199 with penicillin/streptomycin and glutamine (all from Gibco Life Technologies). After 45 minutes the bone slices were washed vigorously and placed in a 96 well plate in minimum essential medium with Hanks' salts (Gibco Life Technologies), with $0.1 \%$ bovine serum albumin (Sigma), L-glutamine, 100 IU benzyl penicillin/ml (Gibco Life Technologies), and $100 \mu \mathrm{g}$ streptomycin/ml (Gibco), and incubated at $37^{\circ} \mathrm{C}$ in a humidified atmosphere of $5 \% \mathrm{CO}_{2} / 95 \%$ air. Salmon calcitonin (sCT) (kindly provided by Rhone-Poulenc Rorer, Pennsylvania, USA) was added to the cultures at final concentrations of $0.1 \mathrm{pg} / \mathrm{ml}$ to 10 $\mathrm{ng} / \mathrm{ml}$. After 18 hours the bone slices were washed in PBS, fixed in formalin, and stained in $0.1 \%$ toluidine blue (Sigma) for five minutes. The area of bone resorption on the bone slices was quantified using reflected light and an image analysis system (Seescan). Bone resorption was expressed as the total (mean) plan area (SEM) of resorption per bone slice. Statistical significance was determined by Student's $t$ test.

The cells were later removed from the bone surfaces by immersing the cells in sodium hypochlorite for five minutes. They were then sputter coated with gold and the bone slices in their entirety were scanned for bone resorption 
using a Cambridge Stereoscan S90 scanning electron microscope (Cambridge Instruments) (with the kind permission from Professor of $\mathrm{T}$ $\mathrm{J}$ Chambers and technical assistance from $\mathrm{Mr}$ $\mathrm{R}$ Moss in Department of Histopathology, St George's Hospital Medical School, London SW17).

Cells were also sedimented onto bone slices to stain them for tartrate resistant acid phosphatase. Staining for tartrate resistant acid phosphatase and the $\alpha_{v} \beta_{3}$ subunit of the vitronectin receptor using monoclonal antibody $23 c 6,{ }^{17}{ }^{18}$ was carried out using conven-
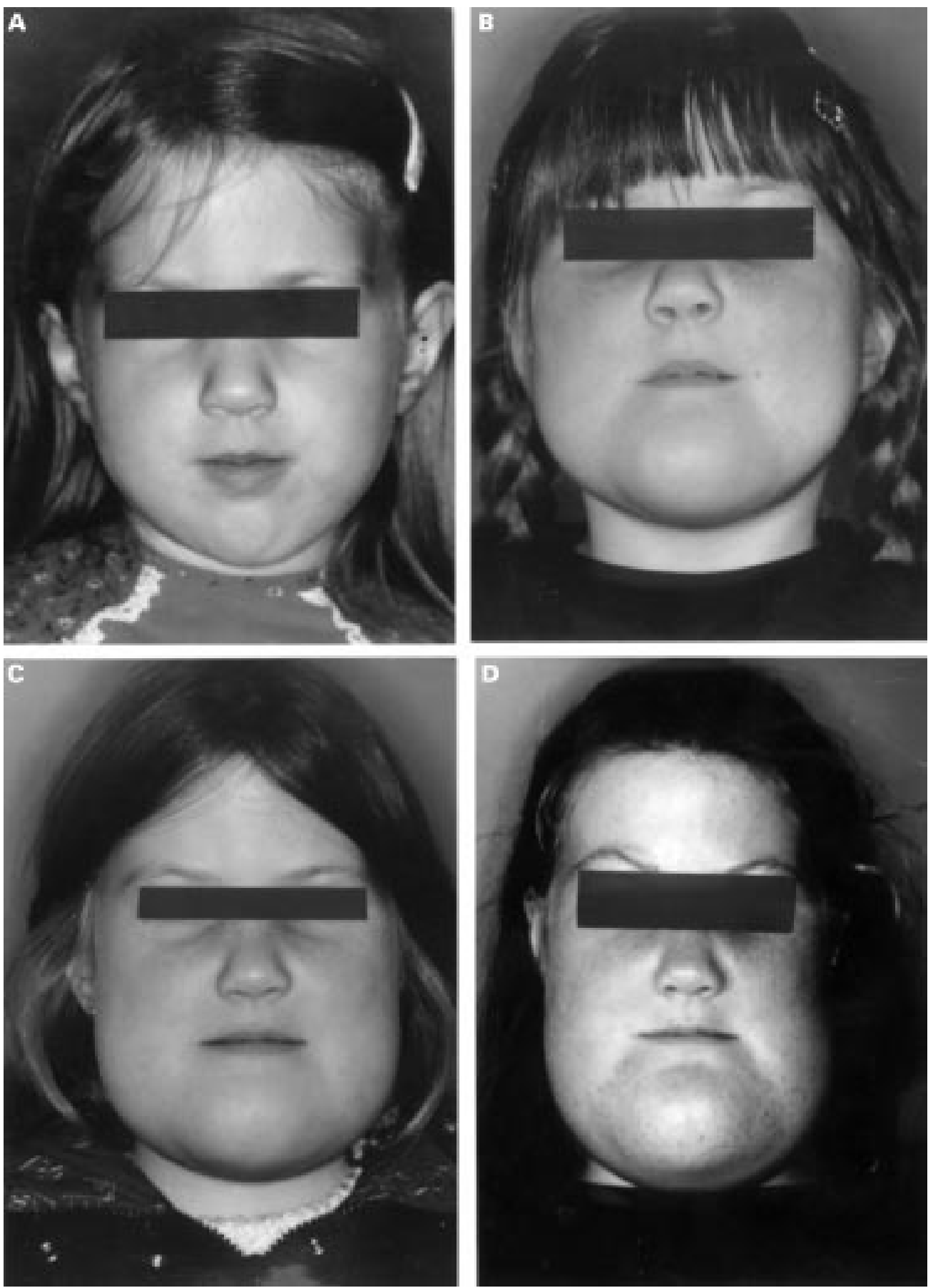

Figure 2 Child $A$ at $4,8,9$, and 13 years of age $(A-D)$. The features of cherubism are most severe at the age of 13 . At 4 years of age, the child would be considered normal if the photograph were examined in isolation, but when studied in sequence it is clear that the early stages of cherubism are present and that there is slight puffiness of the cheeks. To preserve anonymity the eyes are obscured and the severe proptosis is not seen.

tional techniques. The substrate used for the former was alkaline phosphatase and for the latter, naphthol AS-B1 phosphate. Tartrate resistance was assessed in the presence of 0.05 $M$ sodium tartrate. The cultures were counterstained with toluidine blue.

CYTOGENETIC STUDIES

Venous blood $(10 \mathrm{ml})$ was taken from two siblings who are severely affected by cherubism. High resolution cytogenetic studies were carried out by conventional techniques on these samples. ${ }^{19}$

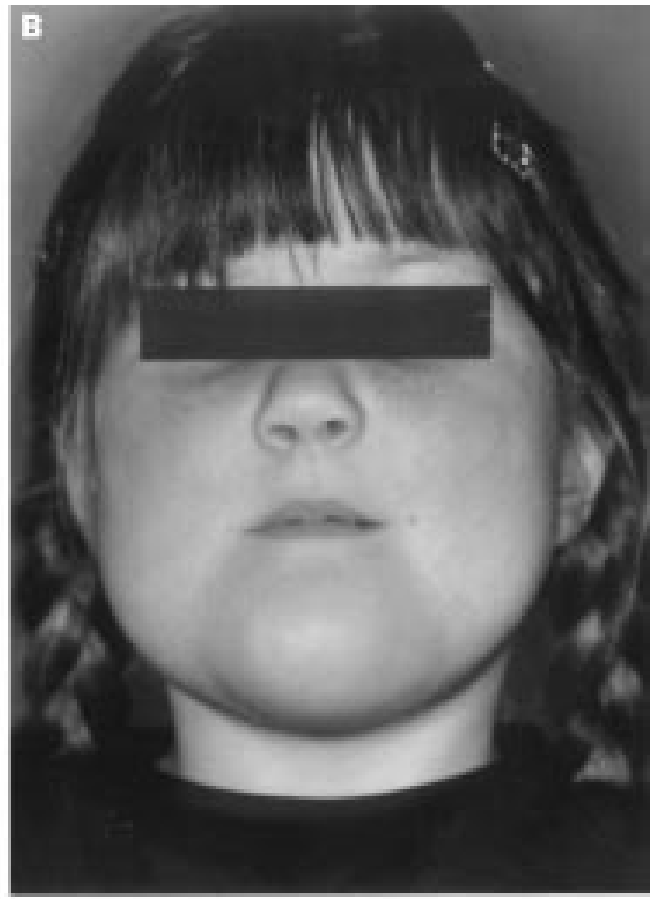

lo 

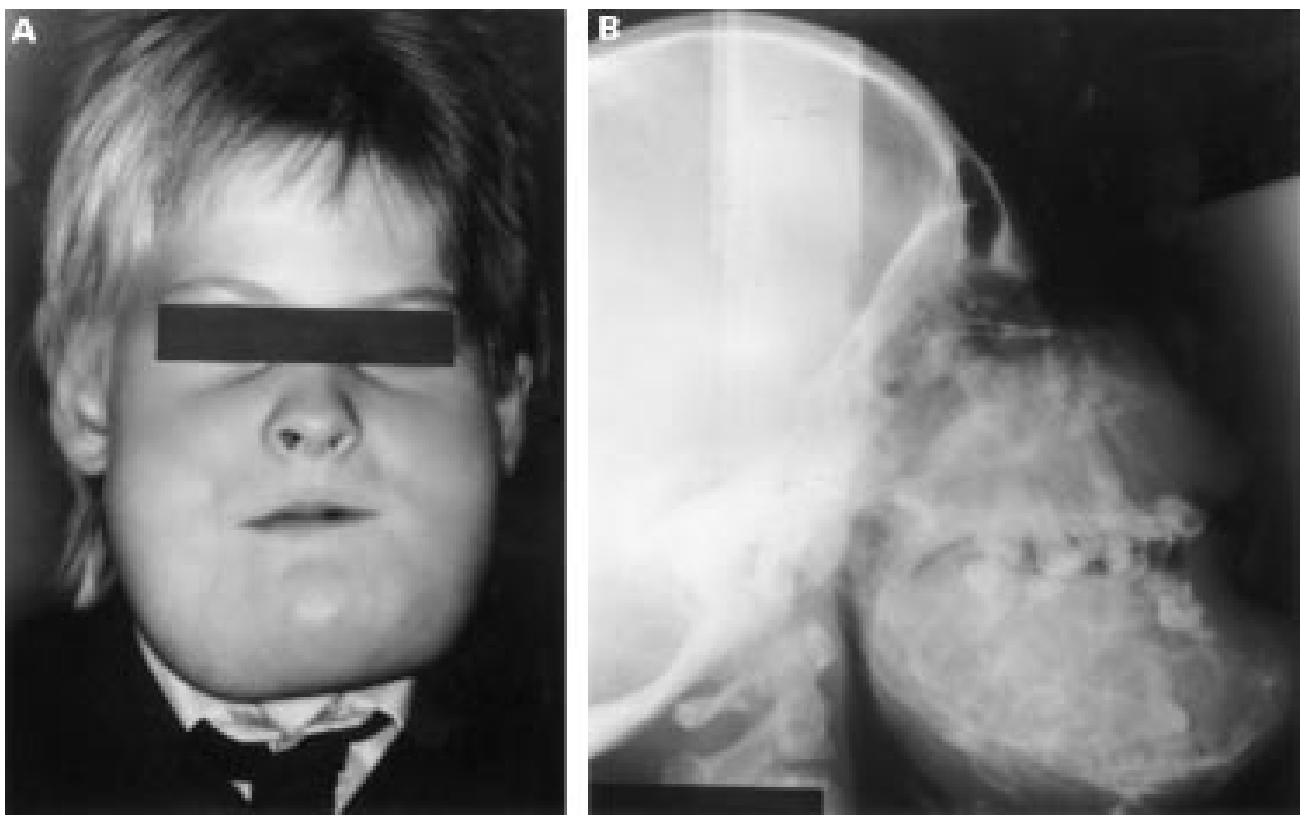

Figure 3 Photograph $(A)$ and $x$ ray $(B)$ of child $C$ at 12 years of age. The deformity of the jaw seen in the photograph is the result of marked overgrowth of the mandible and maxilla with cyst formation in the bone. Note the loss of teeth and partial obstruction of the nasal cavity.

BIOCHEMICAL ANALYSIS

Blood and urine samples were collected after overnight fasting. The second void urine sample was collected on rising and used for analysis. Routine determinations of calcium and alkaline phosphatase were made on an SMAC II analyser (Technicon Instruments). Urine hydroxyproline was measured by the method of Prokof and Udenfriend. ${ }^{20}$ Total pyridinium and deoxypyridinium cross links were measured by high performance liquid chromatography, using a fluorimetric detector. ${ }^{21}$ Serum osteocalcin concentrations were determined by radioimmunoassay using a kit supplied by Incstar Corporation. Serum parathyroid hormone $(\mathrm{PTH})$ was measured using Magic Lite (Ciba Corning). Parathyroid hormone related peptide (PTH-rP) (1-86) was measured using a two site immunoradiometric assay from the Nichols Institute (San Juan Capistrano, California, USA). All these assays were performed according to the manufacturer's instructions. Age matched reference ranges for serum calcium and total alkaline phosphatase were derived from the data base at Worthing Hospital and that for serum calcitonin from the endocrine unit at Imperial College School of

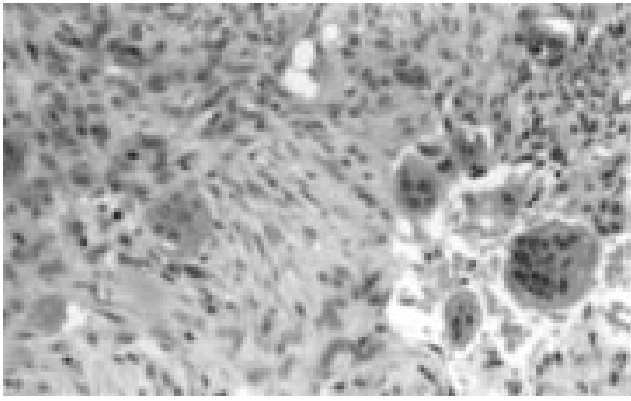

Figure 4 Haematoxylin and eosin stained tissue section from the jaw of child $A$ at the age of 13 years. There are many multinucleate cells set in a mononuclear cell population of stromal cells.
Medicine at Hammersmith Campus, London. We are grateful to Dr W Frazer at The Royal Liverpool Hospital for the PTH-rP reference range for children, as this is not available in a published report. The reference range for serum osteocalcin was provided in the manufacturer's instructions. Those for urine hydroxyproline to creatinine ratios and for urine
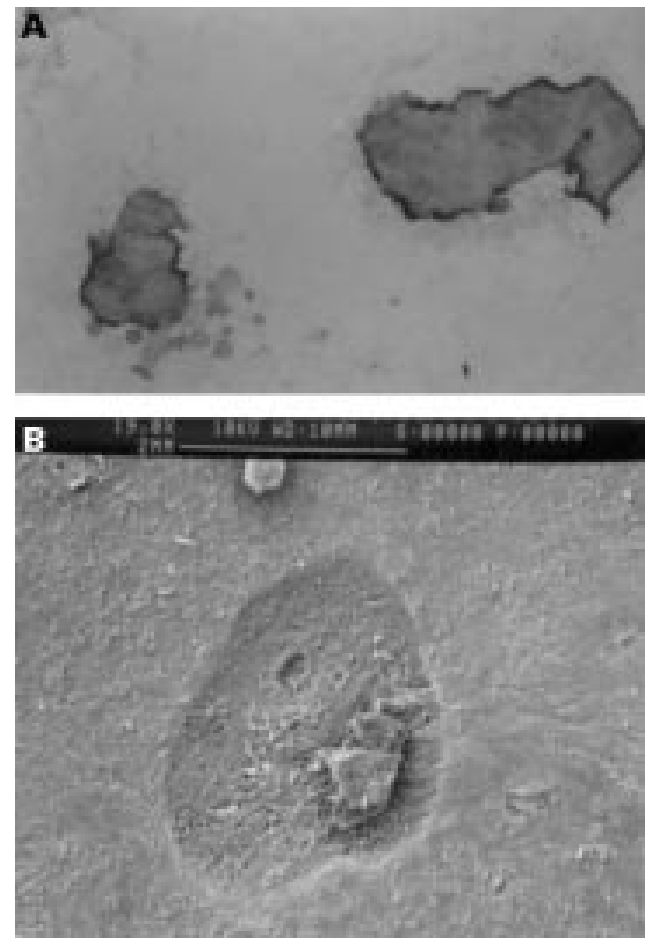

Figure 5 (A) Multinucleate cells from the jaw of child $A$, dabbed onto a glass slide, are immunoreactive for monoclonal antibody $23 \mathrm{c6} 6$ (this identifies the vitronectin receptor), which is expressed on the surface membrane of osteoclasts (×200). (B) A scanning electron photomicrograph of a surface excavation on devitalised bovine bone which was resorbed by an osteoclast from the jaw tumour of child $A$. 


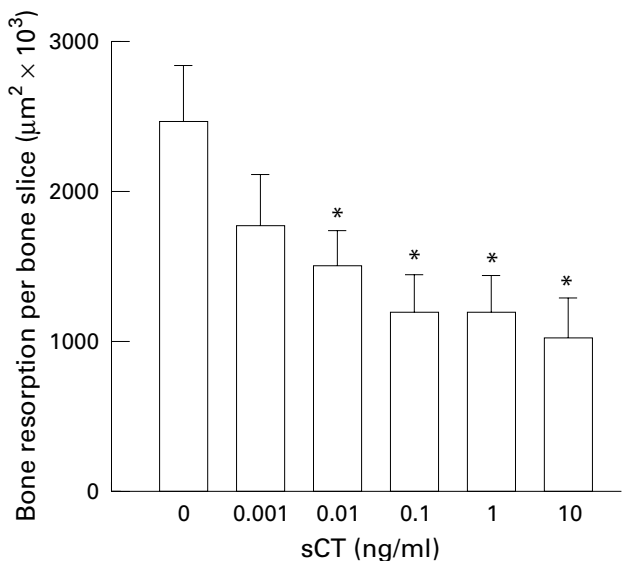

Figure 6 Plan area of bone resorbed per bone slice after 18 hours of incubation of cells from a cherubism lesion in child $A$, in the presence and absence of salmon calcitonin ( $(C T)$ $(n=6) .{ }^{\star} p<0.001 v$ control (no sCT added).

pyridinium and deoxypyridinium cross links were previously reported by Wharton et al and Rauch et al, respectively. ${ }^{22}$

\section{Results}

HISTOLOGY AND IN VITRO STUDIES

Histological sections of the lesion showed a spindle cell stroma in which there were large numbers of multinucleate giant cells (fig 4). The multinucleate cells stained strongly with monoclonal antibody 23c6 (fig 5) and tartrate resistant acid phosphatase (not shown). We also found excavations on the surface of the bone slices when cells from the cherubic lesions were cultured on them (fig 5); this area was reduced significantly in a dose-response manner in the presence of sCT (fig 6).

CYTOGENETIC STUDIES

High resolution cytogenetic studies failed to detect any chromosomal abnormalities.

BIOCHEMISTRY

Serum calcium was found to be within the normal range in the four children with cherubism. We also measured intact serum PTH in this condition for the first time, and report it to be unequivocally normal in all four affected children (table 1). Serum alkaline phosphatase and osteocalcin were also found to be normal for ages, and electrophoresis showed mainly bone subfractions, which is the normal isoenzyme pattern for the children's ages. PTH-rP was certainly not raised in the three most affected children (table 1), but this measurement was made after they had been treated with calcitonin for a month as the assay was not available during the early part of the study and old samples were not suitable for analysis. The finding of a normal PTH-rP concentration in the least affected but untreated child $\mathrm{B}$ is therefore important to note (table 1).

Urine from all four children showed high fasting calcium to creatinine ratios compared with published reference ranges. ${ }^{24}{ }^{25}$ However, urine salt excretion, which is now recognised to be associated with hypercalciuria, was not measured at this time. Urine analysis of hydroxyproline to creatinine ratios gave values at the upper end of reported normal range (table 1). ${ }^{22}$ Likewise, the urine concentrations of pyridinium and deoxypyridinium cross links appeared to be at the upper end of the normal range (table 1$).^{23}$

\section{Discussion}

We found that the multinucleate cells in cherubic lesions had phenotypic characteristics of osteoclasts: they labelled with antibody $23 \mathrm{c} 6$, which identifies the $\alpha_{v} \beta_{3}$ subunit of the vitronectin receptor, and with tartrate resistant acid phosphatase. Furthermore cells from the cherubic lesions resorbed bone in vitro and this function was reduced in the presence of SCT, implying that the multinucleate cells were responsible for the bone resorption. Our findings raise the possibility that treatment of cherubic individuals with calcitonin may curtail the disease and reduce the need for surgery. It is not possible to determine from these data whether bone resorption was reduced by downregulating osteoclast activity or whether osteoclast numbers were reduced in the presence of calcitonin, since the osteoclasts were not counted. However, it has previously been shown that inhibition of calcitonin induced bone resorption is associated with

Table 1 Biochemical results in four children with cherubism

\begin{tabular}{|c|c|c|c|c|c|}
\hline Variable & $\begin{array}{l}\text { Reference } \\
\text { ranget }\end{array}$ & Child A & Child B & Child $C$ & Child D \\
\hline Age (years) & & 14 & 12 & 10 & 8 \\
\hline \multicolumn{6}{|l|}{ Serum values } \\
\hline Total calcium (mmol/l) & $2.1-2.7$ & 2.56 & 2.44 & 2.61 & 2.58 \\
\hline Alkaline phosphatase (IU/l) & & $81(50-150)$ & $283(100-400)$ & $353(100-400)$ & $398(100-300)$ \\
\hline PTH $(\mathrm{pmol} / \mathrm{l})$ & $1.3-7.6$ & 2.9 & 1.1 & 2.3 & 3.0 \\
\hline PTH-RP (pmol/1) & $<1.4$ & $0.4^{\star}$ & 0.2 & $0.3^{\star}$ & $0.4^{\star}$ \\
\hline Osteocalcin (ng/ml) & $<11$ & 8.58 & $(-)$ & 9.86 & 10.0 \\
\hline Calcitonin $(\mathrm{ng} / \mathrm{ml})$ & $<0.08$ & $<0.04$ & $<0.04$ & $<0.04$ & $<0.04$ \\
\hline Serum electrophoresis & & \multicolumn{4}{|c|}{ Normal in all four children } \\
\hline \multicolumn{6}{|l|}{ Urine (fasting samples) } \\
\hline Calcium/creatinine $(\mathrm{mmol} / \mathrm{mol})$ & $<700$ & 1097 & 839 & 733 & 702 \\
\hline $\begin{array}{l}\text { Hydroxyproline/creatinine } \\
(\mathrm{mmol} / \mathrm{mol})\end{array}$ & & $118(22-94)$ & $216(45-123)$ & $182(39-104)$ & $132(36-107)$ \\
\hline Pyridinoline/creatinine $(\mathrm{nmol} / \mathrm{mmol})$ & & $198(117 \pm 69)$ & $302(186 \pm 80)$ & $244(186 \pm 80)$ & $337(159 \pm 52)$ \\
\hline $\begin{array}{l}\text { Deoxypyridinoline/creatinine } \\
(\mathrm{nmol} / \mathrm{mmol})\end{array}$ & & $55(29 \pm 23)$ & $84(50 \pm 23)$ & $86(50 \pm 23)$ & $124(43 \pm 13)$ \\
\hline
\end{tabular}

Pyridinoline and deoxypyridinoline ratios to creatinine are raised compared with age related reference ranges in the boy child $\mathrm{D}$ at 8 years. ${ }^{23}$ The other children show cross links at the higher end of the age related reference range. + The figures in brackets show the normal age related ranges. ${ }^{23}{ }^{\star}$ Denotes samples taken after one month's treatment with nasal calcitonin. 
reduced cell motility and a dramatic shape change, and that these morphological changes are reversed when the calcitonin is removed from the medium. ${ }^{26}$ This suggests that calcitonin inhibits bone resorption by inducing a quiescent state in osteoclasts and not by reducing osteoclast numbers.

It is thought that osteoblasts play a central role in osteoclast recruitment, formation, and resorption, ${ }^{27}{ }^{28}$ and it has been proposed that osteoclast-rich lesions-including the osteoclastoma, central and peripheral granulomas of the jaw, and osteoclast-rich malignant fibrous histiocytoma-contain a cell of the osteoblast lineage which is responsible for the recruitment of the osteoclast or its precursor into these lesions. ${ }^{13}{ }^{1429}$ It is likely that a similar mechanism accounts for the presence of osteoclasts in cherubic jaws, particularly since there is a conspicuous stromal cell population in these tumours, similar to that described in other giant cell lesions of the jaw. Since calcitonin mediates its effect directly on the osteoclast and not on the osteoblast-type cell, it would be predicted that if the disease were to remit as a result of calcitonin treatment, it should relapse if the treatment was stopped. Interestingly, this is what happened to one of the children from Harris's group. ${ }^{15}$ However, when treatment was restarted and given for a further six months, the disease went into remission and there was no sign of a recurrence five years later. Harris's other two children were identified as being clinically and radiologically healed after a single course of calcitonin. The fourth patient in that group was an adult, who responded well to treatment initially but required surgical excision for the lesion to be cured. It is not clear why these children were cured with calcitonin treatment, but it is possible that their disease was curtailed by the treatment and then went into spontaneous remission at puberty. This possibility is proposed because cherubism, which has marked similarities to giant cell granulomas of jaw, is known to remit spontaneously when children reach puberty. ${ }^{12}$ The reason why this occurs is not clear but since osteoclast formation is reduced by sex steroids, ${ }^{30}$ and since plasma concentrations of oestradiol and testosterone are increased at puberty, it suggests that the genetic defect responsible for the localised increase in osteoclasts in cherubism is overridden and normalised by the physiologically increased synthesis of sex steroids.

The most common use for calcitonin, as an antiresorptive agent, is in postmenopausal women for the prevention of osteoporosis. ${ }^{31}$ In this condition it reduces bone loss transiently, but over a period of time the effect of the drug declines, an effect known as "escape." ${ }^{32}$ Recent experiments have shown that an important component of escape from inhibition of bone resorption by osteoclasts is resistance of the mature osteoclasts to calcitonin, as a result of downregulation of the expression of the calcitonin receptor. ${ }^{33}$ If this escape phenomenon were to occur to children, calcitonin treatment would be of little value as children with cherubism would require treatment for several years.

Documentation of the biochemistry in the aggressive form of cherubism is limited. Serum calcium has generally been reported as normal and we confirmed this in the current study. This is not unexpected in view of the localised site of the disease and it is consistent with the report from Davis et al, who found that serum calcium and PTH concentrations were within the normal range in a patient with multifocal osteoclastic lesions. ${ }^{34}$ However, in contrast to our findings in cherubism, this individual had high levels of PTH-rP, alkaline phosphatase (not separate components), and serum calcitonin. Urine analysis was not performed in this study.

The urine hydroxyproline to creatinine ratio is largely a reflection of total collagen in the fasting state: it is not specific for bone collagen and furthermore it is known to be significantly higher in growing children than in adults. ${ }^{22} \mathrm{We}$ also measured bone turnover using the fluorescent assay for total pyridinium and deoxypyridinium cross links (which are newer and more specific markers of bone turnover, the latter being more specific for bone collagen ${ }^{35}$ ). The concentrations of these markers were repeatedly at the upper end of the reference data of Rausch $e t a l,{ }^{23}$ and it is interesting to speculate that they may reflect the activity of the localised bone disease in these children. However, it is well documented that there is marked day to day interindividual variation, especially in children, in the levels of urinary pyridinium and deoxypyridinium cross links. Hence we do not recommend that this assay is used in isolation as a means of monitoring children with cherubism, particularly since our data are derived from a small number of patients.

Identification of the genetic mutation which is responsible for cherubism would have widespread implications in terms of understanding the biology of the osteoclast. The osteoclast is a rare cell in the human body and its poor availability makes study of its biology difficult. Studies which have had the greatest impact on our understanding of the biology of the osteoclast have come from recent molecular investigations of natural and genetically engineered mutations in mice. ${ }^{36-38}$

Cherubism, as one of the very few genetically determined osteoclastic lesions in the human body, is an ideal disease for the study of osteoclast biology and pathology.

We are grateful to Beverley Holland, Cytogenetic Unit, St Mary's Hospital, London, for performing the cytogenetic studies.

1 Peters WJN. Cherubism: a study of twenty cases from one family. Oral Surg Oral Med Oral Pathol 1979;47:307-11.

2 Jones WA. Familial multilocular cystic disease of the jaws. Am F Cancer 1933;17:946-50.

3 Topazian RG, Cotish ER. Familial fibrous dysplasia of the aws (cherubism): report of a case. Oral Surg 1965;23:55966.

4 Grunebaum M, Tiqva P. Non familial cherubism: report of two cases. F Oral Surg 1973;31:632-5.

5 Kaugars GE, Svirsky JA. Cherubism: diagnosis, treatment and comparison with central giant cell granulomas and giant cell tumour. Oral Surg Oral Med Oral Pathol 1992;73: 369-74.

6 Killey HC, Seward GR, Kay LW. An outline of oral surgery, part II. Bristol: Wright and sons, 1978:92-4. 
7 Wayman JB. Cherubism: a report on three cases. $\mathrm{Br}$ f Oral Surg 1978;16:47-56.

Aral Surg Oral Med Oral Pathol 1965;20:648-53.

9 Pindborg JJ, Kramer IRH, Torlini H. Histological typing of odontogenic tumours, jaw cysts and allied lesions. Geneva: World Health Organisation, 1976.

10 Regezi JA, Sciubba JJ. Oral pathology: clinical-pathologic correlations. Philadelphia: WB Saunders, 1989:379-82, 437-9.

11 Jaffe HL. Giant cell reparative granuloma, traumatic bone cyst and fibrous (fibro-osseous) dysplasia of the jaw bones. Oral Surg Oral Med Oral Pathol 1953;6:159-75.

12 Riefkohl R, Georgiade GS, Georgiade NG. Cherubism. Ann Plastic Surg 1985;14:85-9.

13 Chambers TJ, Fuller K, McSheehy PMJ, et al. The effect of calcium-regulating hormones on bone resorption by isolated osteoclastoma cells. F Pathol 1985;145:297-305.

14 Flanagan AM, Tinkler SMB, Horton MA, et al. The multinucleate cells in giant cell granulomas of the jaw are osteonucleate cells in giant cell granul
clasts. Cancer 1988;62:1139-45.

15 Harris $M$. Central giant cell granulomas of the jaws regress with calcitonin therapy. Br f Oral Maxillofac Surg 1993;31: 89-94.

16 Chambers TJ, Revell PA, Fuller K, et al. Resorption of bone by isolated rabbit osteoclasts. F Cell Sci 1984;66:383-99.

17 Horton MA, Lewis D, McNulty K, et al. Monoclonal antibodies to osteoclastomas (giant cell bone tumours): definition of osteoclast-specific cellular antigens. Cancer Res 1985;45:5663-9.

18 Davies J, Warwick J, Tutty N, et al. The osteoclast functional antigen, implicated in the regulation of bone resorption, is biochemically related to the vitronectin receptor. $\mathcal{f}^{\mathrm{Cell}} \mathrm{Bio}$ 1989;109:1817-26.

19 Gosden CM, Davidson C, Robertson M. In: Rooney DE, Czepulkowski BH, eds. Human cytogenetics: a practical approach. New York: Oxford University Press, 1992:31-54.

20 Prokof DJ, Udenfriend S. A specific method for the analysis of hydroxyproline in tissues and urine. Anal Biochem 1960; of hyd $1: 228$.

21 Ibrahim S, Mojiminiyi S, Barron J. High performance liquid chromatographic determination of pyridinium crosslinks in
serum, urine and dialysate of patients in chronic renal failserum, urine and dialysate of patients
ure. Ann Clin Biochem 1996;33:31-5.

22 Wharton BA, Gough G, Williams A, et al. Urinary total hydroxyproline:creatinine ratio. Range of normal, and clinical applications in British children. Arch Dis Child 1972;47:74-9.

23 Rauch F, Schonau E, Woitge H, et al. Urinary excretion of hydroxy-pyridinium cross-links of collagen reflects skeletal growth velocity in normal children. Exp Clin Endocrinol 1994;102:94-7.

24 Matos V, van Melle G, Boulat O, et al. Urinary phosphate/creatinine, calcium/creatinine and magnesium/ creatinine ratios in a healthy pediatric population. $\mathcal{F}$ Pediatr 1997;131:252-7.

25 Sweid HA, Bagga A, Vaswani M, et al. Urinary excretions of minerals, oxalate and uric acid in north Indian children. Pediatr Nephrol 1997;11:189-92.

26 Chambers TJ, Magnus CJ. Calcitonin alters behaviour of isolated osteoclasts. F Pathol 1982;136:27-39.

27 Chambers TJ. The cellular basis of bone resorption. Clin Orthop Rel Res 1980;151:283-93.

28 Rodan GA, Martin TJ. The role of osteoblasts in hormonal control of bone resorption. Calcif Tiss Int 1981;33:349-51.

29 Flanagan AM, Chambers TJ. Osteoclasts are present in the giant cell variant of malignant fibrous histiocytoma. 7 Pathol 1989;159:53-7.

30 Sarma U, Edwards M, Motoyoshi K, et al. 17ß-Estradiol inhibits human osteoclast formation in vitro. $\mathcal{F}$ Cell Physiol 1998;175:99-108.

31 Overgaard K, Riis BJ, Christiansen C, et al. Effect of calcitonin given intranasally on early postmenopausal bone loss. BMF 1989; 305:477-9.

32 Silva OL, Becker KL. Salmon calcitonin in the treatment of hypercalcaemia. Arch Intern Med 1973;132:337-9.

33 Wada S, Udagawa N, Nagata N, et al. Calcitonin receptor down-regulation relates to calcitonin resistance in mature mouse osteoclasts. Endocrinology 1996;137:1042-8.

34 Davis JP, Archer DJ, Fisher C, et al. Multiple recurrent giant cell lesions associated with high circulating levels of parathyroid hormone-related peptide in a young adult. $\mathrm{Br} \mathcal{F}$ Oral Maxillofac Surg 1991;29:102-5.

35 James IT, Walne AJ, Perrett D. The measurement of pyridinium crosslinks: a methodological overview. Ann Clin Biochem 1996;33:397-420.

36 Yoshida H, Hayashi S-I, Kunisada T, et al. The murine mutation osteopetrosis is in the coding region of the macrophage colony stimulating factor gene. Nature 1990;345: 442-4.

37 Grigoriadis AE, Wang Z-Q, Cecchini MG, et al. c-Fos: a key regulator of osteoclast-macrophage lineage determination and bone remodeling. Science 1994;266:443-7.

38 Soriano P, Montgomery C, Geske R, et al. Targeted disruption of the c-src proto-oncogene leads to osteopetrosis in mice. Cell 1991;64:693-702. 